\title{
Network marketing innovation and management construction of tourism market in China
}

\author{
Ying Liu \\ Dalian Vocational and Technical College \\ 116035
}

Key words: tourism market; network marketing; innovation; management; construction

\begin{abstract}
In recent years, China's tourism industry has been developing continuously, and has effectively promoted the social and economic benefits. At the same time, the development of tourism industry has put forward higher requirements for the network marketing management innovation and development of China's tourism market. Moreover, the tourism marketing network marketing effectively stimulate the tourists' tourism desire, improve the quality of tourism products, and create a modern tourism service brand. This paper will give an example of China's tourism market network marketing innovation and management strategy, and put forward personal views.
\end{abstract}

\section{Introduction}

The tourism market network marketing undertakes the important function of the final exchange between the tourism product service and the consumer, it is the core of the contemporary tourism enterprise network management, and its essence is to meet the tourist information needs. This requires that tourism enterprises must have the ability to identify tourists needs, analyze the value of tourism products development and promotion, and formulate and implement the right tourism market network marketing strategy. This paper will analyze the definition of tourism market network marketing, and strengthen the interaction of tourism network, do well in customer relationship management; promoting the globalization of tourism marketing network marketing; promoting the publicity work of tourism products through network innovation; innovating tourism market network marketing means, from these four aspects to illustrate the construction scheme of China's tourism market network marketing innovation and management.

\section{Definition of tourism market network marketing}

The tourism market network marketing directly faces the tourists and recognizes the tourists' tourism consumption psychology, determines the target market that the tourism enterprise can provide the best service, and combine with the virtual scene to design the appropriate tourism products, service and experience, in order to meet the needs of the development of China's tourism market. Moreover, the essence of tourism market network marketing is to meet the needs of tourists to tourism information, therefore, all marketing activities of tourism enterprises should be carried out in this center. In addition, the combined elements of tourism market network marketing are divided into five systems, that need, wants and demands, products, value, satisfaction and cost, exchange, transaction and relationship, market [1]. Among them, the need and wants is the basis of the tourism market network marketing activities, need is the tourists' demand for tourism products and related information, and it is also the basic starting point of tourism enterprises designing tourism service products. Wants is the desire of tourists to obtain tourism information, which is the specific pursuit of basic needs. Demands have a specific meaning in the tourism market network marketing, which refers to the wants of tourists to participate in tourism activities and purchase tourism products, which is the market demand for tourism products and services. Tourism enterprises can influence demand by means of network marketing, and stimulate tourists' psychology of tourism consumption.

Products are the products that tourism enterprises provide to the market and can meet the needs and desires of tourists, the concept of products is not limited to the physical, anything that can meet the needs of tourists can be called tourism products. In addition, the service experience of tourists 
has increasingly become an important tourism service product, which brings tourists a spiritual valuable experience, such as enjoying the flowers, appreciating the music fountain, tasting the delicious food and so on. Moreover, the concept is a kind of declaration slogan of tourism enterprises, often through tangible products or intangible services to achieve, tourists recognized a concept that they will continue to purchase the products of tourism enterprises.

The value, satisfaction and cost are interdependent, and tourists make consumption choices based on their understanding of the value provided by tourism products and services, that is, the usefulness or utility of products and services to tourists. The utility of tourism products is usually based on the subjective judgment of the value of tourism products and the cost to be paid. The satisfaction of tourists depends on the comparison of the utility and expected value of tourism products understood by tourists. If the utility of tourism products is lower than the expectations of tourists, the satisfaction of tourists is not high. If the utility meets the expectations of the tourists, the tourists will be satisfied; If the utility exceeds the visitors' expectations, the tourists will be pleasantly surprised ${ }^{[2]}$.

Exchange is the act of providing the tourists with the information or value needed, and obtaining the corresponding value of the object or service. When tourists decide to meet their needs and desires through exchange, tourism marketing is produced. As a way of meeting the needs, the exchange has many advantages, which can make the whole social economy and tourism service industry more efficient. Transaction is the measure unit of tourism marketing, and also the value exchange between tourism enterprises and tourists. Moreover, transaction marketing is an integral part of the relationship marketing, in addition to short-term transactions, tourism marketing personnel must also establish long-term relationship with the tourist groups. This is mainly through commitment and sustained delivery of high-quality tourism products, good services and fair prices to establish strong social and economic ties. Relationship marketing is increasingly important, it emphasizes the long-term nature, its goal is to provide long-term value for tourists, its success scale is the long-term and continuous satisfaction of tourists.

The market is a collection of tourism enterprises and tourists to trade tourism products, composed of tourism enterprises, tourists for the market. The goal of the marketing personnel of contemporary tourism enterprises is to meet the needs and desires of the specific tourism market, to select the best products or services market, and to meet the requirements of tourists through the design and production of tourism products service.

\section{The innovation and management construction scheme of network marketing in China's tourism market}

2.1 Strengthen the interaction of tourism network, do well in customer relationship management. The innovative tourism market network marketing model should pay attention to the communication and interaction between tourism enterprises and tourists, using interactive tourism network to help tourists design a tourism plan for the four seasons of the year, to mine different times tourism resources, to allow tourists to participate in tourism activities in a planned and purposeful manner, to encourage tourists to express their views on the tourism page, to respect the suggestions of tourists, and to solve the problem of tourists.

In addition, after the end of each tourism service activity, tourism enterprises should understand the feedback status of tourists through the network, do well in customer relationship management, and constantly improve the tourism service scheme ${ }^{[3]}$. Moreover, the tourism enterprises can teach tourists to set up the concept of green tourism consumption, pay attention to the protection of tourism resources, maintain the natural state of natural ecological areas, and maintain the unique culture of ancient buildings.

At the same time, the tourism enterprise should pay attention to the customer relationship management, pay attention to the value of the key customers, clarify the management work with the customer as the core, must establish the customer information database and information management system of the tourism enterprise itself, its content should include the customer's consumption information, customer's consumption preference, customer's personal data, etc. Only 
by mastering these, the enterprises can objectively and comprehensively analyze the potential needs of customers and give them satisfaction. Moreover, the tourism enterprises should analyze the shortage of the enterprise in collecting the data of the customers, and improve it.

2.2 Promoting the globalization of tourism market network marketing. Tourism enterprises can use the advantages of network information dissemination speed and large capacity, promote the globalization of tourism market network marketing, provide 24-hour tourism market network marketing services, create good business opportunities for the enterprise, use different languages ( such as Chinese, English, Korean, Japanese, French, etc. ) to make Chinese tourism cultural service products to global market, and promote the internationalization of Chinese tourism industry.

On the other hand, tourism enterprises should construct the micro-blog marketing management mode, guide tourists to participate in tourism activities, understand the aspirations of tourists, and meet the needs of tourists. The " micro-blog marketing" is to use the network microblogging platform to communicate with customers, the main function of the marketing management mode is to provide the relevant content of micro-blog tourism and the sharing of the main part of the dissemination of tourism related matters, it can be said that tourism microblogging is a new marketing platform and tourism management. Using micro-blog to travel can through different pictures, video, text information. Using network microblogging marketing, not only fully demonstrates the basic image of tourism purposes, but also improve the tourism service brand and social and economic benefits.

2.3 Innovating the propaganda mode of tourism products with the aid of tourism network. To improve the quality of tourism market network marketing, tourism enterprises can use flash video design to rich tourism web page, and do well in tourism products network publicity work, so that tourists have a comprehensive understanding of tourist attractions, accommodation, diet and local traditional culture and customs. For example, in the publicity of the Summer Palace in Beijing, tourism enterprises can insert landscape photos into the flash video and web pages, and edit the commentary of rich historical and cultural features to inform visitors: the Summer Palace in Beijing is a beautiful Chinese royal garden, mainly composed of Longevity Hill and Kunming Lake. Longevity Hill originally named Urn Hill, Kunming Lake used to call the Urn Hill Park, West Lake. The Ming dynasty built temples and pavilions here, famous for the Wonmyong Temple. The fifteenth year of Qing emperor Qianlong celebrated his mother's 60th birthday, he changed the Urn Hill to Longevity Hill, and built a great kindness of Gratitude, which is the predecessor of Cloud Dispelling Hall, Pavilion of the Fragrance of Buddha, Sea of Wisdom Temple and so on, and transformed the West Lake, renamed as Kunming Lake. The Summer Palace has more than 3000 palace gardens, and is the most complete and largest royal garden ${ }^{[4]}$. This can from the perspective of cultural network to attract tourists, do well in tourism products publicity work.

2.4 Innovating network marketing means of tourism market. Tourism enterprises should pay attention to innovative tourism market network marketing means from the perspective of price strategy, and do the propaganda work of good quality and cheap tourism service. Enterprises can upload cheap tourism landscape photos to the tourism website, in order to attract consumers, access to the tourism market, and reduce the development costs. Secondly, the tourism enterprises should reasonably divide the tourism market network marketing price area, guide tourists to choose the tourist destination according to the demand and specific price. In addition, tourism enterprises can also set up " tourist consumption discussion area " to understand the consumption desire of tourists, help tourists to formulate tourism programs, meet the expectations prices of tourists.

\section{Concluding remarks:}

In conclusion, the tourism market network marketing directly faces the tourists and recognizes the tourists' consumption psychology, determines the target market which tourism enterprises can provide the best service, and combines the virtual scene to design the appropriate tourism products, services and experience to meet the needs of the development of the tourism market in our country. To innovate tourism market network marketing management model, tourism enterprises should 
fully design and optimize the interactive tourism network, promote the tourism market network marketing globalization, do well in tourism products publicity; Innovate tourism market network marketing means to meet the price expectations of tourists .

\section{Reference:}

[1] Li Yang. Discussion on some problems in the network marketing management of tourism market [ j ]. Jilin university, 2012 ( 12: 1 )

[2] Ou Yangzheng. Research on the development of non - material cultural heritage tourism take Lotus flowers folk song as an example [j ]. Lanzhou university, 2012 ( 05: 2 )

[3] Liu Tinghan. Discussion on the innovation tourism market network marketing management mode thinking and practice [ $j$ ]. Chengdu University of Technology, 2015 ( 04: 3 )

[4] Yuan Yaoqing. Study on spatial effect and integrated development mode of tourism resources group and tourism development of Dunhuang Mogao Caves in Gansu province[ $\mathrm{j}$ ]. Central South University, 2012 ( 11: 4 ) 